\title{
Technical Note: Chemical enhancement of germination in curly mesquite seed
}

\author{
ANDREW RALOWICZ, CHARLES MANCINO, AND DAVID KOPEC
}

Authors are former graduate associate, assistant professor, and associate extension specialist, Department of Plant Sciences, University of Arizona. Tucson 85721, respectively.

\begin{abstract}
Curley mesquite (Hilaria belangeri (Steud.) Nash), an important range grass in the southwestern United States, is being evaluated for soil and resource conservation, and range reseeding. Experiments were performed on seed from plants grown with supplemental irrigation to investigate the effects of chemical treatments on germination. Gibberellic acid (GA) at $0.7,1.4,2.1$, and $2.8 \mathrm{~m} M$ significantly enhanced total germination over the control. Low concentrations of $\mathrm{GA}(0.14,0.28,0.42$, and $0.56 \mathrm{mM})$ did not significantly improve germination compared to the control. These results suggest that $0.7 \mathrm{mM} \mathrm{GA}$ is the critical concentration to positively affect total germination of curly mesquite seed. Previous reports indicate that curly mesquite seed do not germinate well. However, rapid germination and high percentages in these experiments suggest that our current concept of germinability in curly mesquite seed may be incorrect.
\end{abstract}

Key Words: Hilaria belangeri, range grass, gibberellic acid, Poaceae

Curly mesquite (Hilaria belangeri) is a palatable, nutritious range grass of the southwestern United States and is being evaluated for soil and resource conservation, and range reseeding. Limited research has been devoted to improving this species because of early reports of poor reproduction by seed on the range (Cory 1948), and poor germination $(<20 \%)$ in the laboratory (USDA 1948, Merrill and Young 1962, Kneebone 1985). Pilot investigations by our laboratory demonstrated rapid germination. These findings suggest that our current concept of germinability of curly mesquite seed may be flawed. Improving germination of caryopses (hereafter referred to as seed) may promote the use of curly mesquite for range seeding.

The objective of this study was to test whether gibberellic acid treatments increase germination of curly mesquite seed. A second objective was to determine a least chemical concentration that adequately increases germination of seed of this species.

\section{Materials and Methods}

Plants were collected in 1987 from Pima, Santa Cruz, and Cochise counties, Arizona, grown in a greenhouse and transplanted during 1988 into a nursery at the Univ. of Arizona Campus Agricultural Center (Tucson). The nursery was established on a Pima loamy sand (Typic Torrifluvent) and sprinkler irrigated.

Mature spikes were bulk harvested from the nursery on 10 Sep.

The authors wish to acknowledge the financial support of the U.S. Golf Association along with the assistance of the SCS Plant Materials Center (Tucson, Arizona), Dr. Robert Kuehl (Arizona Experiment Station Statistition), Dr. James A. Young (range scientist, USDA-ARS Reno, Nevada), and the Arizona Crop Improvement Association (Tucson, Arizona). The authors also thank Dr. Bruce Roundy for critical review of this manuscript. Paper 7179 of the Arizona Agricultural Experiment Station.

Manuscript accepted 22 Nov. 1991.
1988. Spikes were stored in paper bags at room temperature. Seed were separated from fascicles by hand threshing on a rubbing board, cleaned with a pneumatic seed cleaner, and stored in a paper envelope at room temperature on 17 Sep. 1988. These seed were used for all experiments, which were conducted in the same germination chamber.

Experiments were conducted with 8 and 12-week old seed. These experiments involved 18 replications of experimental units, a petri dish containing germination paper moistened with $6 \mathrm{ml}$ of the respective solution and 25 seeds. Treatments were 5 gibberellic acid (GA) concentrations $(0,0.7,1.4,2.1,2.8 \mathrm{mM}$, and $0,0.14,0.28$, $0.42,0.56 \mathrm{mMGA}$ in experiments I and II, respectively). These concentrations were selected based on a pilot experiment where $1.4 \mathrm{mM}$ GA increased total germination compared to the control $(n=27$ replications). Germination was rapid in the pilot experiment: more than half of the total germination occurred during the first 48 hours of incubation (data not shown).

Experimental units were sealed with paraffin strips to prevent solution evaporation and were incubated in a controlled environment with 12-hour cycles of $35^{\circ} \mathrm{C} / 23^{\circ} \mathrm{C}$ with constant fluorescent illumination (J.A. Young, 1988, pers. commun.). A seed was considered germinated when the radicle and coleoptile were at least 1 mm long. Number of germinated seed was recorded at 24-hour intervals for 96 hours. Cumulative germination percentages were computed after 48,72 , and 96 hours. Experiments were terminated after 96 hours as no seeds germinated thereafter.

Cumulative germination percentages were arcsin square root transformed (Snedecor and Cochran 1980). Regression analysis was performed on cumulative germination with time (duration of incubation), and was used to determine the effect of GA concentration on total germination ( 96 hours).

\section{Results and Discussion}

In experiment $I$, regression analysis of cumulative germination with the duration of incubation showed no significant GA by time interaction, indicating that $\mathrm{GA}$ effects were statistically equivalent over time. Therefore, GA data were pooled. A $2^{\text {nd }}$ degree polynomial best described the relationship between duration of incubation and germination (Fig. 1); however, the majority (73\%) of the response was linear. The predicted time to $50 \%$ germination was 28.5 hours.

Throughout the experiment, germination of seed within the 2.8 mM GA treatment was greater than that of the control treatment; similarly, from 48 to 96 hours, mean cumulative germination percentages of seed within the GA treatments overlapped while remaining distinctly separate from the control (Fig. 1). A significant $(P<0.046)$ linear relationship existed between $G A$ concentration and total germination (data not shown). This relationship $(y=$ $4.6 x+83.5)$ was weak $\left(r^{2}=0.023\right)$ due to the variation in germina- 

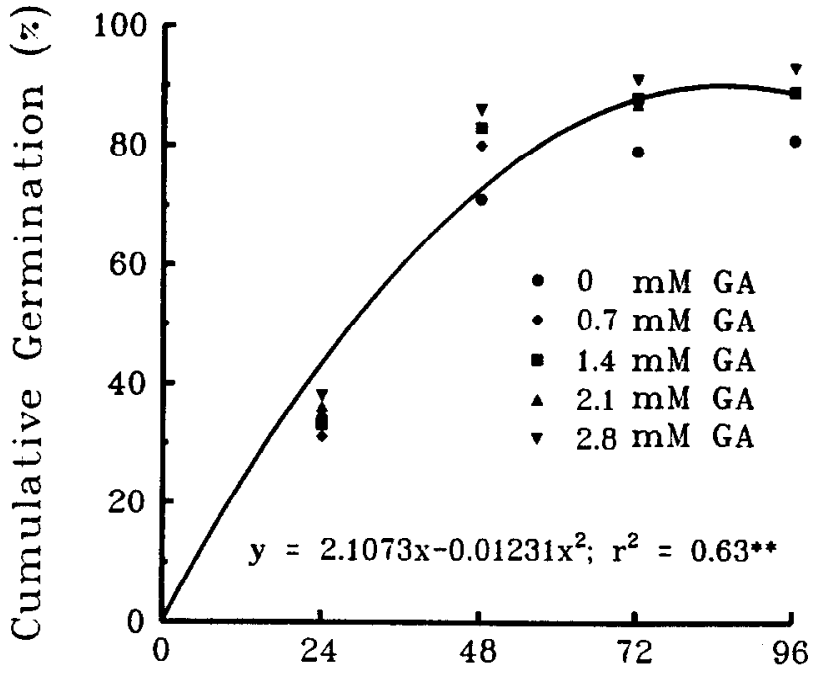

Hours of incubation

Fig. 1. Average cumulative germination percentage means of curly mesquite seed treated with gibberellic acid (GA) concentrations increasing from 0 to $2.8 \mathrm{~m} M$ plotted across the duration of incubation. A symbol represents the mean of 18 replications per $G A$ concentration. The coefficient of determination ( $\left.r^{2}\right)$ is significant at $P<0.01$.

tion $(\mathrm{C} . \mathrm{V} .=32 \%, \mathrm{SE}=0.03)$. In experiment $\mathrm{II}$, no significant relationship existed between $\mathrm{GA}$ and total germination percentage (data not shown). Total germination averaged $63 \%$ with $57 \%$ germination in 24 hours.

Comparison of the average total germination percentages of the control treatments in experiments I (80\%) and II $(63 \%$, data not shown) with the control (34\%) in the pilot experiment suggests that seed aging improves germination, as seed were 4,8 , and 12 weeks old in these 3 experiments. Attention also must be drawn to the extent and rapidity of germination. These results contradict the earlier reports of poor laboratory germination (USDA 1948, Merrill and Young 1962, Kneebone 1985). Seed age, storage conditions, and incubation temperatures were not given in these reports. Because the data clearly illustrate that germination is rapid and high, we must question the concept of poor germinability in curly mesquite.

\section{Conclusions}

Gibberellic acid concentrations as low as $0.7 \mathrm{mM}$ significantly improved the germination of curly mesquite seeds. Only marginal improvement in germination was gained with GA concentrations greater than $0.7 \mathrm{~m} M$, making justification of the GA pregermination treatment questionable. Lower levels of GA were ineffective in improving germination. These inconsistent results, due in part to the inherent variation in germination of the seed lot, make identification of a critical GA concentration difficult.

\section{Literature Cited}

Cory, V.L. 1948. Curly mesquitegrass in Texas and northern Mexico. Wrightia 1:214-217.

Kneebone, W.R. 1985. Hilaria belangeri, a rediscovered potential low maintenance arid land turf. p. 285-288. In: F. Lemaire (ed.), Proc. 5th Internat. Turfgrass Res. Conf. Institut National Res. Agron. Pub., Paris, France.

Merrill, L.B., and V.A. Young. 1962. Germination and root establishment in curly mesquitegrass. Texas Agr. Exp. Sta. Misc. Pub. 615.

Snedecor, G.W., and W.C. Cochran. 1980. Statistical methods. The Iowa State Univ. Press, Ames.

USDA 1948. Grass. USDA yearbook of agriculture, 1948. U.S. Gov. Print. Office, Washington, DC. p. 746. 